\title{
Psychological functioning in children suspected for mitochondrial disease: the need for care
}

\author{
Kim F. E. van de Loo ${ }^{1 *}$ (D) José A. E. Custers², Saskia Koene ${ }^{3,4}$, Inge-Lot Klein², Mirian C. H. Janssen ${ }^{5}$,
} Jan A. M. Smeitink ${ }^{6}$ and Christianne M. Verhaak ${ }^{1}$

\begin{abstract}
Background: Mitochondrial diseases (MD) are generally serious and progressive, inherited metabolic diseases. There is a high comorbidity of anxiety and depression and limitations in daily functioning. The complexity and duration of the diagnostic process and lack of knowledge about prognosis leads to uncertainty. In this study, we investigated the psychological well-being of children who are suspected for MD and their parents.

Methods: In total 122 children suspected for MD and their parents, received questionnaires as part of standard clinical investigation.

Results: Parent proxy report revealed a lower quality of life (QoL) compared to norms and even more physical problems compared to chronically ill patients. They also reported more behavioral problems in general and more internalizing problems compared to the norms. Most frequent reported somatic complaints were tiredness and pain. Parents did not report enhanced levels of stress regarding parenting and experienced sufficient social support. At the end of the diagnostic process, $5.7 \%$ of the children received the genetically confirmed diagnosis of MD, $26 \%$ showed non-conclusive abnormalities in the muscle biopsy, 54\% did not receive any diagnosis, and the remaining received other diagnoses. Strikingly, children without a diagnosis showed equally $\mathrm{QoL}$ and behavioral problems as children with a diagnosis, and even more internalizing problems.

Conclusions: This study highlights the psychological concerns of children with a suspicion of MD. It is important to realize that as well as children with a confirmed diagnosis, children without a diagnosis are vulnerable since explanation for their complaints is still lacking.
\end{abstract}

Keywords: Mitochondrial diseases, Psychology, Quality of life, Behavioral problems, Parenting stress, Diagnostic process

\section{Background}

Mitochondrial diseases (MD) are rare and inherited metabolic diseases, which may present with any symptom, at any age and any mode of inheritance [1]. In

\footnotetext{
* Correspondence: Kim.vandeLoo@radboudumc.nl

${ }^{1}$ Radboud Institute for Health Sciences, Department of Medical Psychology, Radboud Center for Mitochondrial Medicine, Amalia Children's Hospital, Radboud University Medical Center, Geert Grooteplein Zuid 10, P.O. Box 9101, 6500HB Nijmegen, The Netherlands

Full list of author information is available at the end of the article
}

general, these are serious and progressive diseases, with an unpredictable disease course. The overall incidence rate is approximately 1:5000 live births $[2,3]$. Mitochondria play an important role in the energy production of the cell. Organs with the highest energy requirement, like the brain and the muscles, are most likely to be affected [4]. There is a wide variety in genetic and biochemical involvement as well as in phenotypic expression [5]. MD could be caused by a mutation in

(c) The Author(s). 2020 Open Access This article is licensed under a Creative Commons Attribution 4.0 International License, which permits use, sharing, adaptation, distribution and reproduction in any medium or format, as long as you give appropriate credit to the original author(s) and the source, provide a link to the Creative Commons licence, and indicate if changes were made. The images or other third party material in this article are included in the article's Creative Commons licence, unless indicated otherwise in a credit line to the material. If material is not included in the article's Creative Commons licence and your intended use is not permitted by statutory regulation or exceeds the permitted use, you will need to obtain permission directly from the copyright holder. To view a copy of this licence, visit http://creativecommons.org/licenses/by/4.0/. The Creative Commons Public Domain Dedication waiver (http://creativecommons.org/publicdomain/zero/1.0/) applies to the data made available in this article, unless otherwise stated in a credit line to the data. 
the mitochondrial DNA (mtDNA) or nuclear DNA (nDNA). The diagnosis of MD is acquired through multiple steps; the clinical presentation (complaints, signs and symptoms, inheritance), clinical chemistry, metabolic studies, pathological evaluation, biochemical and genetic testing [6]. To date, no cure is available.

The impact of having MD is major for the child and his/her parents. The most burdensome complaints in children are fatigue, behavior and speech disturbances, epilepsy and muscle weakness, and a high degree of limitations in daily activities [1]. Furthermore, anxiety and depression are common in children with $\operatorname{MD}[7,8]$, with an even higher comorbidity compared to children with other types of inborn errors of metabolism and compared to patients with Sotos syndrome [8]. The severe limitations children experience and the large variability in clinical manifestations also result in a high impact on the well-being of the caregiver [9]. Parents often experience stress and worries [10, 11]. Parenting stress is higher when there are more hospitalizations and increased use of special services, and when there is more organ involvement [11].

It seems clear that the psychological impact of having MD is high. Less is known about the psychological functioning of children and their parents who are in the diagnostic process. The diagnostic process is complex and may take years between onset of first symptoms and confirmed diagnosis [12]. This lengthy time as well as a lack of knowledge about the diagnosis leads to uncertainty and stress [12]. In children and their parents, to our knowledge, no research exists addressing the psychological well-being during the diagnostic process. The primary objective of the current study is to investigate the psychological well-being of children who are suspected for MD and their parents.

\section{Methods Participants}

All parents of children ( $<18$ years) suspected for MD, who received a muscle biopsy at the Radboud Center for Mitochondrial Medicine (RCMM), Radboudumc Amalia Children's Hospital in Nijmegen (the Netherlands) between January 2010 and April 2019 were included. Indication for a muscle biopsy was determined based on international guidelines at time of assessment.

\section{Procedure}

Parents received questionnaires as part of a standard healthcare program before muscle biopsy. This program was started in January 2010 and inclusion ended in April 2019. Parents had to be fluent in Dutch in order to understand the questionnaires. After completion of the questionnaires, the results of the final diagnosis (based on muscle biopsy studies, mtDNA and/ or whole exome sequencing), were also investigated.

\section{Materials \\ Demographic factors and disease characteristics}

Demographic and disease characteristics, like duration of health complaints and involved specialists, were assessed by a 20 -item questionnaire filled in by one parent of every child.

\section{Child outcome measures}

Quality of life (QoL) was assessed with the Pediatric Quality of Life Inventory (PedsQL) [13]. Parent proxy report (children aged 5 to 18 years) was used. A higher score indicates a better health-related QoL [13].

Behavioral problems of the child were assessed with the Child Behavior Checklist (CBCL) (parent-reported questionnaire) [14, 15]. The CBCL provides scores on global, internalizing and externalizing behavioral problems. The CBCL is divided into two age categories: 1,5 to 5 years and 6 to 18 years. Available norms provide age and gender-standardized T-scores $(M=50 ; S D=10)$. Total, internalizing and externalizing $\mathrm{T}$-scores $\geq 60$ and syndrome scale $\mathrm{T}$-scores $\geq 65$ represent the borderline, whereas scale $\mathrm{T}$-scores $\geq 64$ and syndrome scale $\mathrm{T}$-scores $\geq 70$ represent the clinical range in the general population $[14,15]$.

\section{Parental outcome measures}

Parenting stress was assessed with the Parenting Stress index (PSI), short version (Nijmeegse Ouderlijke Stress Index NOSIK) [16]. This questionnaire evaluates the stress parents experience in raising their child in the age of 1 to 13 years. Scores were rated into normal (score mothers < 74; score fathers $<64$ ), subclinical (score mothers 74-89; score fathers $64-78$ ) and clinical levels of parenting stress (score mothers $>89$; score fathers $>78$ ).

Parental perceived social support was assessed with the Inventory for Social Reliance (ISR) [17]. The ISR evaluates the social support network of parents of children in the age from 0 to 18 years. The total score was used as a measure of experienced social support. Scores above 10 were rated as normal/ sufficient amount of social support, 7-9 indicated a low amount, and 6 or below were seen as insufficient amount of social support [18].

\section{Statistical analysis}

All statistical analyses were conducted by using the Statistical Package for Social Sciences (SPSS) for Windows version 25.0 (IBM Corp., Armonk, NY). Normal distribution of continuous data was assessed using ShapiroWilk test of normality.

Parent report scores of the PedsQL were compared, using one sample $\mathrm{t}$-tests, to the norm scores of a healthy 
population sample and a general chronic health condition sample, defined in Varni et al. (2006) as "a physical or mental health condition that has lasted or is expected to last at least 6 months and interferes with the child's activities" [19].

The parent proxy report of behavioral problems (CBCL) was assessed with different age versions. Since subscales of both versions using similar concepts, we used the sum score of each concept for calculations when possible. The percentage of behavioral problems above the clinical cutoff were calculated. The total, internalizing and externalizing problems were compared to the norms $[14,15]$. Assessment of depression in a somatic population is difficult as vital aspects of depression are also apparent as symptoms of somatic conditions (e.g. less active). Following assessment of depression in adult populations [20], we deleted items relating to vital functioning in the assessment of depression. We used both the original scale (CBCL withdrawn/ depressed), as well as an adjusted subscale (CBCL withdrawn/depressed $\left._{\text {adj }}\right)$, in which the somatic items are replaced by the mean score of the remaining subscale items. Specific items of the somatic complaints which could also be core symptoms of MD were investigated by using percentages of item scores $>2$. Chi-square tests, linear-by-linear association, were used to investigate differences between children with or without a diagnosis in rated items $(0,1,2)$ of somatic complaints. As an indication of possible not met needs we investigated how many children with behavioral problems (clinical score on the total, internalizing or externalizing scale), had support from a dedicated specialist, psychologist or remedial educationalist.

Differences between children with (MD, uncertain abnormalities or other diagnoses) and without a diagnosis were investigated by using independent samples t-test or in case of non-normal distribution, a Mann-Whitney $\mathrm{U}$ test. Variables of interest (mothers report of the PedsQL Total scale, CBCL Total, Internalizing, Externalizing, Anxious/Depressed, Withdrawn/Depressed ${ }_{(\text {adj) }}$, Somatic complaints and both PSI and ISR of fathers and mothers) were used for analyses.

\section{Results}

\section{Demographics and disease characteristics}

In total 122 children and their parents participated (Table 1). The majority of children perceived health complaints for more than 3 years. In almost $75 \%$ of the children, one or more specialist(s) were involved. Most frequently involved were physiotherapy (55\%), followed by speech therapy and a dietician (both $28 \%$ ). A psychologist or remedial educationalist were involved in respectively 17 and $11 \%$ of all children.
Results from the muscle biopsy and further diagnostics (genetics) show that $54.9 \%$ of all children did not receive any diagnosis, and only $5.7 \%$ received the diagnosis of having MD. $26.2 \%$ of the children showed at the time non-conclusive abnormalities in the muscle biopsy and genetic analysis. The remaining $12.3 \%$ received other genetic diagnoses, and in of one patient there is no final diagnosis up to date.

\section{Child outcomes \\ Quality of life}

Parent proxy-report revealed a lower QoL in total and on all subscales compared to the general population (Table 2). Compared to other patients with a chronic health condition, fathers and mothers also reported more problems with physical functioning in their child and mothers also a lower QoL in general. In contrast, fathers reported a better social functioning for their children compared to other patients with a chronic health condition.

\section{Child behavior}

Mean scores, standard deviations, as well as percentage scoring in the clinical range of the CBCL are described in Table 3. Mothers and fathers both reported higher scores on the total scale (Mothers $\mathrm{X}^{2}[1]=12.67, p=.000$, fathers $\left.\mathrm{X}^{2}[1]=8.65, p=.003\right)$, and more internalizing problems (Mothers $X^{2}[1]=138.72, p=.000$, fathers $X^{2}$ $[1]=57.32, p=.000)$ in the clinical range compared to the norms.

A total of $12.3 \%$ of the children show withdrawn/depressed behavior according to their mothers and 13.3\% as reported by their fathers. When adjusting for ambiguous items which both load on withdrawn/depressed as well as disease symptoms, child's behavior was rated as withdrawn/depressed in 7.0\% (mothers report) and 4.8\% (fathers report) of the children. Scores of the withdrawn/ depressed adjusted scale were significantly lower, indicating less concerns, after correcting for the somatic items in both mothers $(\mathrm{t}(113)=-9.57, p=.000)$ and fathers report $(\mathrm{t}(82)=-7.11, p=.000)$.

Most frequent reported somatic complaints were tiredness (mothers report: 51.9\%, fathers report: 40.7\%) and pain (mothers report: $34.2 \%$, fathers report: $27.7 \%$ ).

In total, 52 of the 113 children showed behavioral problems on one of the scales (total, internalizing or externalizing), of which 9 (17\%) received help from a psychologist or remedial educationalist.

\section{Parental outcome measures \\ Parenting stress}

Compared to a clinical population, both fathers and mothers reported less parenting stress. Mothers also reported less parenting stress compared to the non-clinical 
Table 1 Demographic variables and disease/ health related characteristics

\begin{tabular}{l} 
Demographics \\
\hline Mean age \\
Boys \\
Child living at home \\
School/childcare \\
- Non \\
- Regular \\
- Special \\
Nationality Dutch \\
Level of education: \\
- Elementary school \\
- Secondary education \\
- Lower vocational education \\
- Intermediate vocational education \\
- Higher vocational education \\
- University \\
Having a job \\
Marital status: \\
- Married \\
- Living together \\
- Single parent
\end{tabular}

Children N (\%,
8.4 years $(0-17)$
$67(54.9 \%, 122$
$115(100 \%)$
$9(7.8 \%, 115)$
$85(73.9 \%)$
$21(18.3 \%)$

$107(97.3 \%, 110)$

$94(92.2 \%, 102)$

$0(0 \%, 108)$

$13(12.0 \%)$

$7(6.5 \%)$

$56(51.9 \%)$

$26(24.1 \%)$

$6(5.6 \%)$

$72(65.5 \%, 110)$

$87(76.3 \%, 114)$

$18(15.8 \%)$

$6(5.3 \%)$

$3(2.6 \%)$
$3(2.9 \%, 105)$

$8(7.6 \%)$

$9(8.6 \%)$

$52(49.5 \%)$

$19(18.1 \%)$

$14(13.3 \%)$

$95(91.3 \%, 104)$

\section{Disease/ health related characteristics}

Duration health complaints

$$
\text { - }<1 \text { year }
$$

$\cdot 1-2$ years

- $>3$ years

Treatment in other care instances

Involvement of other specialists in total

$$
\begin{aligned}
& 11(9.8 \%, 112) \\
& 18(16.1 \%) \\
& 83(74.1 \%) \\
& 87(75.0 \%, 116) \\
& 85(74.6 \%, 114) \\
& 32(28.1 \%, 114) \\
& 63(55.3 \%, 114) \\
& 19(16.7 \%, 114) \\
& 13(11.4 \%, 114) \\
& 12(10.5 \%, 114) \\
& 32(28.1 \%, 114) \\
& 16(14.0 \%, 114)
\end{aligned}
$$

$59(56.7 \%, 104)$

$65(67.7 \%, 96)$

$73(63.5 \%, 115)$

$43(41.3 \%, 104)$

Care leave

Health problems: In family

- Mother/Father

- Brothers/sisters

Other concerns in general

Diagnoses

- No diagnosis

$67(54.9 \%)$

- Mitochondrial disease

$7(5.7 \%)$

- Non-conclusive abnormalities 
Table 1 Demographic variables and disease/ health related characteristics (Continued)

\begin{tabular}{llll}
\hline Demographics & Children N (\%, Total) & Family/ general information & Mothers \\
\hline - Confirmed other diagnosis & $15(12.3 \%)$ & & Fathers \\
- No diagnosis up to date & $1(0.8 \%)$ & & \\
\hline
\end{tabular}

population. There was no significant difference between fathers and mothers in parenting stress $(\mathrm{t}(67)=-0.46$, $p=.649$ ). In total $5.9 \%$ of the mothers experienced parenting stress in the clinical range and $11.1 \%$ of the fathers (Table 4).

\section{Social support}

Both mothers and fathers experienced more social support compared to the norms [17] and more social support compared to patients with rheumatoid arthritis [18] (Table 4). In total, $98.2 \%$ of the mothers and $97.8 \%$ of the fathers experienced sufficient social support.

\section{Comparison children with and without a diagnosis in psychological functioning}

There was no difference between children with any diagnosis or without a diagnosis in QoL (mothers report: $\mathrm{t}(81)=-.806, p=.422)$ or in total or external behavioral problems (see Table 3). Regarding internal behavioral problems, mothers reported more problems of their children without a diagnosis (mean T-score $=61.35$ ) compared to children with a diagnosis (mean T-score $=56.36$ ). There were no differences between children with or without a diagnosis in the amount of reported somatic complaints, except for headache. Mothers of children without a diagnosis report more complaints of headache in their child compared to children with a diagnosis.

There were no significant differences between the groups with or without a diagnosis in parenting stress (mothers $\mathrm{t}(82)=-.626, p=.533$, fathers $\mathrm{t}(69)=.246$, $p=.806$ ), and social support (mothers $\mathrm{t}(108)=-.447$, $p=.665$, fathers $\mathrm{t}(86)=1.134, p=.260)$.

\section{Discussion}

To the best of our knowledge, this is the first study investigating the psychological well-being of children who are in the diagnostic process of a suspected MD, and their parents. Overall, results showed substantial problems in child psychological functioning, while parents do not report enhanced levels of parenting stress or a lack of social support.

Parent proxy-report revealed a lower QoL on all areas compared to the norms, which is in line with adult studies of patients with proven MD [21, 22]. Children also showed more problems with physical functioning compared to children with other general chronic illnesses, indicating serious impairments.

Regarding behavioral problems, compared to norms, parents reported more problems in general and more internalizing problems specifically in their child, which is in

Table 2 Child's quality of life as reported by their parents (PedsQL)

\begin{tabular}{|c|c|c|c|c|c|c|}
\hline Quality of Life (PedsQL) & $N^{*}$ & Mean (SD) & Norms healthy population ${ }^{\mathbf{a}}$ & Student's t & $\begin{array}{l}\text { Norms chronic ill } \\
\text { population }^{\mathbf{a}}\end{array}$ & Student's t \\
\hline \multicolumn{7}{|c|}{ Parent proxy report- Mother } \\
\hline Total & 84 & $59.57(16.23)$ & 77.61 & $\mathrm{~T}(83)=-10.19, p=.000$ & 64.05 & $\mathrm{~T}(83)=-2.53, p=.013$ \\
\hline Physical & 84 & $47.89(24.60)$ & 79.20 & $T(83)=-11.66, p=.000$ & 66.38 & $\mathrm{~T}(83)=-6.89, p=.000$ \\
\hline Emotional & 84 & $68.87(20.01)$ & 77.65 & $\mathrm{~T}(83)=-4.02, p=.000$ & 64.85 & $\mathrm{~T}(83)=1.84, p=.069$ \\
\hline Social & 84 & $67.26(18.41)$ & 79.51 & $\mathrm{~T}(83)=-6.10, p=.000$ & 63.45 & $\mathrm{~T}(83)=1.90, p=.061$ \\
\hline School & 83 & $61.34(16.40)$ & 73.12 & $\mathrm{~T}(82)=-6.54, p=.000$ & 60.36 & $\mathrm{~T}(82)=.55, p=.588$ \\
\hline Psychosocial & 84 & $65.83(14.47)$ & 76.76 & $\mathrm{~T}(83)=-6.92, p=.000$ & 62.87 & $\mathrm{~T}(83)=1.88, p=.064$ \\
\hline \multicolumn{7}{|c|}{ Parent proxy report- Father } \\
\hline Total & 62 & $60.12(16.87)$ & 77.61 & $\mathrm{~T}(61)=-8.16, p=.000$ & 64.05 & $\mathrm{~T}(61)=-1.83, p=.071$ \\
\hline Physical & 62 & $48.27(24.98)$ & 79.20 & $\mathrm{~T}(61)=-9.75, p=.000$ & 66.38 & $\mathrm{~T}(61)=-5.71, p=.000$ \\
\hline Emotional & 63 & $69.52(19.81)$ & 77.65 & $\mathrm{~T}(62)=-3.26, p=.002$ & 64.85 & $\mathrm{~T}(62)=1.87, p=.066$ \\
\hline Social & 61 & $68.87(17.28)$ & 79.51 & $\mathrm{~T}(61)=-4.85, p=.000$ & 63.45 & $\mathrm{~T}(61)=2.47, p=.016$ \\
\hline School & 61 & $61.13(16.43)$ & 73.12 & $\mathrm{~T}(60)=-5.70, p=.000$ & 60.36 & $\mathrm{~T}(60)=.37, p=.717$ \\
\hline Psychosocial & 63 & $66.53(14.73)$ & 76.76 & $\mathrm{~T}(62)=-5.51, p=.000$ & 62.87 & $\mathrm{~T}(62)=1.97, p=.053$ \\
\hline
\end{tabular}

* Of the 89 children who were 5 years or older, 84 parents filled in the PedsQL. Mother report only: $N=22$, father report only: $N=0$, mother and father report: $N=62$

${ }^{a}$ Norms Varni et al., 2006 (the pedsql as a population health measure) 
Table 3 Child's behavioral problems as reported by their parents $(\mathrm{CBCL})$

\begin{tabular}{|c|c|c|c|c|c|}
\hline \multirow[t]{2}{*}{ Scale/subscale } & \multicolumn{2}{|l|}{ Mothers report } & \multicolumn{2}{|l|}{ Father report } & \multirow{2}{*}{$\begin{array}{l}\text { Diagnosis vs no diagnosis, } \\
\text { mothers report }\end{array}$} \\
\hline & Mean T-score (SD) N = 113-115 & $\begin{array}{l}\% \text { in clinical } \\
\text { range }\end{array}$ & Mean T-score (SD) N = 82-84 & $\begin{array}{l}\% \text { in clinical } \\
\text { range }\end{array}$ & \\
\hline Total score & $55.91(10.04)$ & $18.6^{* *}$ & $54.15(10.64)$ & $18.3^{*}$ & $\mathrm{~T}(110)=1.64, p=.104$ \\
\hline Internalizing & 59.35 (11.27) & $40.7^{* *}$ & $57.71(11.58)$ & $32.9^{* *}$ & $\mathrm{~T}(110)=2.36, p=.020^{\mathrm{d}}$ \\
\hline Externalizing & $48.36(10.08)$ & 7.9 & $47.84(9.88)$ & 7.2 & $\mathrm{~T}(111)=-.24, p=.811$ \\
\hline Anxious/depressed & $55.66(8.08)$ & 5.2 & $55.00(7.52)$ & 3.6 & $U=1276, p=.069$ \\
\hline Somatic complaints & $65.44(10.37)$ & 36.8 & $63.40(11.22)$ & 25.3 & $\mathrm{~T}(111)=1.49, p=.140$ \\
\hline Pain $^{c}$ & & 34.2 & & 27.7 & $x^{2}(1)=1.21, p=.272$ \\
\hline Tiredness ${ }^{c b}$ & & 51.9 & & 40.7 & $X^{2}(1)=492, p=.483$ \\
\hline Headache & & 16.1 & & 14.5 & $x^{2}(1)=4.12, p=.042^{d}$ \\
\hline Stomach pain/cramps ${ }^{c}$ & & 14.2 & & 11 & $x^{2}(1)=1.19, p=.276$ \\
\hline Obstipation ${ }^{c}$ & & 9.6 & & 11.9 & $x^{2}(1)=.45, p=.503$ \\
\hline Doesn't eat well ${ }^{\mathrm{ca}}$ & & 25.0 & & 26.7 & $x^{2}(1)=.40, p=.530$ \\
\hline Withdrawn/depressed & $59.01(8.47)$ & 12.3 & $57.77(7.74)$ & 13.3 & $\mathrm{~T}(111)=1.71, p=.090$ \\
\hline Withdrawn/depressed $_{a d j}$ & $56.34(7.54)$ & 7.0 & $55.65(6.91)$ & 4.8 & $\mathrm{~T}(111)=.62, p=.535$ \\
\hline Attention problems & $58.26(8.26)$ & 8.8 & $57.67(8.80)$ & 8.4 & \\
\hline Aggressive behavior & $53.69(6.69)$ & 3.5 & $53.29(5.97)$ & 2.4 & \\
\hline Emotional reactive $(1.5-5)^{\mathrm{a}}$ & $56.86(9.96)$ & 8.6 & $56.83(6.27)$ & 0 & \\
\hline Sleep problems $(1.5-5)^{\mathrm{a}}$ & $55.23(6.85)$ & 2.9 & $52.86(4.76)$ & 0 & \\
\hline Social problems $(6-18)^{b}$ & $57.80(7.68)$ & 5.1 & $57.17(8.15)$ & 9.3 & \\
\hline Thought problems $(6-18)^{b}$ & $58.13(9.21)$ & 12.7 & $58.56(9.46)$ & 16.7 & \\
\hline Rule breaking behavior (6-18) ${ }^{\mathrm{b}}$ & $52.33(4.12)$ & 1.3 & $52.54(4.30)$ & 1.9 & \\
\hline
\end{tabular}

\section{${ }^{*} P<.05$}

${ }^{* *} P<.001$

aversion $1.5-5$ years, $N=35$ mothers, 29 fathers

bersion 6-18 years, $N=79$ mothers, 54 fathers

'Item of the subscale somatic complaints. Rated as percentage of scores $>2$ ('very often/ true' as response)

${ }^{d}$ patients without a diagnosis have a higher mean score compared to patients with a diagnosis

line with other literature in children with chronic diseases [23]. Although both the CBCL total and internalizing scale are including somatic items, a meta-analysis [23] showed that elevated levels of both scales remained after controlling for confounding aspects of items related to somatic condition. Surprisingly, children without a diagnosis showed more internalizing problems compared to children with a diagnosis, indicating a high need for help in these children. Based on results of this study, we cannot explain these findings. The underlying mechanisms for behavioral problems may be different in these groups and should be investigated in future research.

Table 4 Parental outcome measures: parenting stress (PSI) and social support (ISR)

\begin{tabular}{llllllll}
\hline & $N$ & Mean (SD) & \% in clinical range & Non-clinical population & Student's t & Clinical population & Student's t \\
\hline PSI & & & & & & & \\
Mothers & 85 & $47.80(20.23)$ & $5.9 \%$ & $54.4^{\mathrm{a}}$ & $\mathrm{T}(84)=-3.009^{*}$ & $85.9^{\mathrm{a}}$ & $\mathrm{T}(84)=-17.368^{* *}$ \\
Fathers & 72 & $49.10(20.89)$ & $11.1 \%$ & $48.5^{\mathrm{a}}$ & $\mathrm{T}(71)=.243$ & $70.4^{\mathrm{a}}$ & $\mathrm{T}(71)=-8.653^{* *}$ \\
ISR & & & & & & \\
Mothers & 111 & $17.01(3.79)$ & $1.8 \%$ & $15.1^{\mathrm{b}}$ & $\mathrm{T}(110)=5.302^{* *}$ & $14.5^{c}$ & Wilcoxon, $p=.000$ \\
Fathers & 89 & $16.82(3.76)$ & $2.2 \%$ & $15.1^{\mathrm{b}}$ & $\mathrm{T}(88)=4.318^{* *}$ & $14.5^{c}$ & Wilcoxon, $p=.000$ \\
\hline
\end{tabular}

\section{$* P<.05$}

${ }^{* *} P<.001$

${ }^{\mathrm{a}}$ Norms De Brock 1992

${ }^{b}$ Norms van Dam-Baggen and Kraaijmaat (1992)

'Huiskes Kraaijmaat Bijlsma 2004 
As mentioned before, anxiety and depression are common in children with MD $[7,8]$ suggesting a possible link with abnormal central nervous system energy metabolism [7]. This study also showed a high percentage of anxious/depressed behavior and withdrawn/depressed behavior. After correcting for possible somatic symptoms, the percentage of experienced withdrawn/depressed complaints dropped significantly. Furthermore, we did not find any differences between children with or without a diagnosis. An explanation could be that the withdrawn/ depressed complaints may not solely be inherent to the disease, but could also be correlated to other factors, for instance inherent to a long history of experiencing specific somatic complaints.

It is known that the somatic complaints subscale of the CBCL is difficult to interpret in children with chronic disease, since items could overlap with illness specific symptoms [23, 24]. On item-level, results revealed a remarkable high percentage of tiredness and pain in children suspected for MD, which are also core symptoms of the disease. There was no difference in these items between children with a diagnosis compared to children without a diagnosis. Surprisingly, children without a diagnosis more frequently reported complaints of headache, indicating debilitating somatic problems in this group.

Contradictory to what was expected $[10,11]$, the majority of the parents did not report parenting stress and mothers reported even less parenting stress compared to the general population. Although there was no difference found between parents of children with or without a diagnosis, this study examined parenting stress before diagnosis, instead of afterwards. A diagnosis of MD brings along, e.g. more hospitalizations, and an increased use of special healthcare services, which is correlated with higher parenting stress [12]. It is important to note that the measurements and thereby the concepts of parenting stress were different between studies. Another explanation could be that parents in our study experienced sufficient social support from their environment, which is seen as a healthy coping behavior, related to less parenting stress [11]. Finally, being in the diagnostic phase could also influence the amount of reported concerns. Possibly the child's well-being is the pith of the matter at time of assessment and parents interpret their child's behavior in light of the possible disease and therefore not so much as 'stressful' but rather in light of compassion and sympathy. It would be interesting to monitor parenting stress after the diagnostic process, especially when there is no diagnosis, to investigate the impact of the possible disease on the perception of parenting stress.

In this cohort of patients suspected for MD, 7 out of the 122 children received a genetically confirmed diagnosis while $26 \%$ of the children showed non-conclusive abnormalities in the muscle biopsy without a yet confirmed genetic mutation. When interpreting these results, it is important to keep in mind that this study started in 2011, and since then the available genetic knowledge and diagnostic tools for mitochondrial disease have markedly improved. Despite this, there are still several limitations in the diagnostic steps required for a diagnosis, amongst which is a lack of understanding of the role of the entire genome in mitochondrial function [25]. We expect that in some of the children with observed non-conclusive abnormalities in the muscle biopsy, future studies will reveal pathogenic mutations. However, for others these might not be discovered due to e.g. non-genetic external factors hampering proper mitochondrial functioning like muscle disuse.

At the end of the diagnostic process, not limited to mitochondrial disease only, more than half of the patients did not receive any diagnosis explaining their debilitating complaints. Given the fact that we found that these children experience the same amount of psychological problems and physical complaints as children with a diagnosis, and even more concerns regarding internalizing problems and headache, these children are especially vulnerable. In the Netherlands these patients do not have automatically the same access to care as patients with a confirmed diagnosis, since they do not fit in a standard care program. For these children, we strongly recommend screening for psychological problems and provide access to care they need.

Having a child with serious complaints that are unexplained confronts parents of children with a rare disease with serious uncertainty. Uncertainty regarding medical conditions especially exists in situations that are ambiguous, complex and unpredictable [26], all applicable to the complaints of children in this study. A lack of diagnosis leaves patients and parents with even more uncertainty. Studies on the impact of rare diseases on children and their parents stress the impact of the long diagnostic process and the diagnostic delays [27, 28]. This long period could seriously impact on health of children and their families. Not only because of possible medical health care needs stay unmet, also the impact of uncertainty regarding the child's health and the look for diagnostics and adequate care means a serious burden. Health care providers could guide parents through possible additional diagnostic trajectories, and by supporting them in dealing with uncertainty, and focus on aspects of their life they can control. This paper stresses the importance of keeping these children and their parents in our focus.

When investigating the met needs of all included children, with or without a diagnosis, only $17 \%$ of the children with behavioral problems received help from a specialist on child behavior, leaving out $73 \%$ with a need 
for help. By including assessment on psychological health, preferably by standardized questionnaires and a psychologist in diagnostic procedures, adequate help can be provided in an early phase.

When interpreting the above-mentioned results, it is important to take note of the strengths and limitations. A strength is the relatively large sample size. Secondly, by screening in the beginning of the diagnostic process, before diagnosis, perceived complaints were not influenced by knowing if they did or did not have the disease. A limitation is the large time span of this study, since diagnostic criteria and possibilities have been improved. Furthermore, due to age limitations of various questionnaires, not all patients and parents filled in the same questionnaires. Finally, since all patients filled in questionnaires as part of standard care, no information regarding e.g. fatigue in children aged $<6$ years, was available, which is the core complaint of MD in children [1].

\section{Conclusions}

This study highlights the psychological concerns of children with a suspicion of MD. It is important to be aware of these problems in an early stage and to provide adequate help, independent of the final diagnosis. Especially the children without any diagnosis confirmed are vulnerable since they remain in uncertainty and do not fit in a standard special care program.

\section{Abbreviations}

CBCL: Child Behavior Checklist; ISR: Inventory for Social Reliance; MD: Mitochondrial diseases; mtDNA: Mitochondrial DNA; nDNA: Nuclear DNA; NOSIK: Nijmeegse Ouderlijke Stress Index; PedsQL: Pediatric Quality of Life Inventory; QoL: Quality of life; RCMM: Radboud Center for Mitochondrial Medicine; SPSS: Statistical Package for Social Sciences

\section{Acknowledgements}

The authors thank Lida Nabuurs, Monique Henselmans, Laura Verbeek, Marion Hermans-Peters, Lonneke de Boer and Maaike de Vries for their contribution in the patientcare and gathering the data.

\begin{abstract}
Authors' contributions
KvdL was involved in conception and design, data collection, analysis and interpretation, and drafting the article. JC was involved in the conception and design of the study, analysis and interpretation, and critically reviewed the manuscript. SK, IK, MJ and JS were involved in the conception and design of the study, interpretation of the results and critically reviewed the manuscript. CV was involved in conception and design of the study, data collection, analysis and interpretation, and critically reviewed the manuscript. All authors read and approved the final version of the manuscript.
\end{abstract}

\section{Funding}

No external funding.

\section{Availability of data and materials}

The dataset used during the current study is available from the corresponding author on reasonable request

\section{Ethics approval and consent to participate}

Present study does not fall within the remit of the Medical Research Involving Human Subjects Act (WMO). The study has been reviewed by the ethics committee on the basis of the Dutch Code of conduct for health research, the Dutch Code of conduct for responsible use, the Dutch Personal Data Protection Act and the Medical Treatment Agreement Act. The ethics committee has passed a positive judgment on the study.

Patients received the questionnaires as standard care, the care as usual. No additional questionnaires were given for the aims of this study. No intervention was given.

\section{Consent for publication}

Not applicable.

\section{Competing interests}

This study was not industry sponsored. KvdL, JC, SK, IK, MJ and CV report no disclosures. Prof. Jan Smeitink is the founding CEO of Khondrion BV.

\section{Author details}

${ }^{1}$ Radboud Institute for Health Sciences, Department of Medical Psychology, Radboud Center for Mitochondrial Medicine, Amalia Children's Hospital, Radboud University Medical Center, Geert Grooteplein Zuid 10, P.O. Box 9101, 6500HB Nijmegen, The Netherlands. ${ }^{2}$ Radboud Institute for Health Sciences, Department of Medical Psychology, Radboud Center for Mitochondrial Medicine, Radboud University Medical Center, Nijmegen, The Netherlands. ${ }^{3}$ Department of Pediatrics, Radboud Center for Mitochondrial Medicine, Radboud University Medical Center, Nijmegen, The Netherlands. ${ }^{4}$ Department of Clinical Genetics, Leiden University Medical Center, Nijmegen, The Netherlands. ${ }^{5}$ Radboud Institute for Molecular Life Sciences, Department of Internal Medicine, Radboud Center for Mitochondrial Medicine, Radboud University Medical Center, Nijmegen, The Netherlands. ${ }^{6}$ Radboud Institute for Molecular Life Sciences, Department of Pediatrics, Radboud Center for Mitochondrial Medicine, Radboud University Medical Center, Nijmegen, The Netherlands.

Received: 4 November 2019 Accepted: 25 February 2020

Published online: 24 March 2020

\section{References}

1. Koene S, Wortmann SB, de Vries MC, Jonckheere Al, Morava E, de Groot IJ, et al. Developing outcome measures for pediatric mitochondrial disorders: which complaints and limitations are most burdensome to patients and their parents? Mitochondrion. 2013;13:15-24.

2. Parikh S, Goldstein A, Karaa A, Koenig MK, Anselm I, Brunel-Guitton C, et al. Patient care standards for primary mitochondrial disease: a consensus statement from the mitochondrial medicine society. Genet Med. 2017;19:118.

3. Schaefer AM, Taylor RW, Turnbull DM, Chinnery PF. The epidemiology of mitochondrial disorders--past, present and future. Biochim Biophys Acta. 1659;2004:115-20

4. Koopman WJ, Willems PH, Smeitink JA. Monogenic mitochondrial disorders. N Engl J Med. 2012;366:1132-41.

5. Smeitink JA, Zeviani M, Turnbull DM, Jacobs HT. Mitochondrial medicine: a metabolic perspective on the pathology of oxidative phosphorylation disorders. Cell Metab. 2006;3:9-13.

6. Parikh S, Goldstein A, Koenig MK, Scaglia F, Enns GM, Saneto R, et al. Diagnosis and management of mitochondrial disease: a consensus statement from the mitochondrial medicine society. Genet Med. 2015;17: 689-701.

7. Koene S, Kozicz TL, Rodenburg RJ, Verhaak CM, de Vries MC, Wortmann S, et al. Major depression in adolescent children consecutively diagnosed with mitochondrial disorder. J Affect Disord. 2009;114:327-32.

8. Morava E, Gardeitchik T, Kozicz T, de Boer L, Koene S, de Vries MC, et al. Depressive behaviour in children diagnosed with a mitochondrial disorder. Mitochondrion. 2010;10:528-33.

9. Sofou K. Mitochondrial disease: a challenge for the caregiver, the family, and society. J Child Neurol. 2013;28:663-7.

10. Read CY. The demands of biochemical genetic disorders: a survey of mothers of children with mitochondrial disease or phenylketonuria. J Pediatr Nurs. 2003:18:181-6.

11. Senger BA, Ward LD, Barbosa-Leiker C, Bindler RC. Stress and coping of parents caring for a child with mitochondrial disease. Appl Nurs Res. 2016; 29:195-201

12. Senger BA, Ward LD, Barbosa-Leiker $C$, Bindler RC. The parent experience of caring for a child with mitochondrial disease. J Pediatr Nurs. 2016;31:32-41. 
13. Varni JW, Seid M, Kurtin PS. PedsQL 4.0: reliability and validity of the Pediatric Quality of Life Inventory version 4.0 generic core scales in healthy and patient populations. Med Care. 2001;39:800-12.

14. Achenbach TM, Rescorla LA. Manual for the ASEBA Preschool Forms \& Profiles. Burlington: University of Vermont Research Center for Children, Youth, \& Families; 2000.

15. Achenbach TM, Rescorla LA. Manual for the ASEBA school-age forms and profiles. Burlington: University of Vermont Research Center for Children, Youth, \& Families; 2001.

16. De Brock AJLL, Vermulst AA, Gerris JRM, Abidin RR. NOSI, Nijmeegse ouderlijke stress index. Lisse: Swets \& Zeitlinger; 1992

17. Van Dam-Baggen R, Kraaimaat F. De inventarisatielijst sociale betrokkenheid (ISB): Een zelfbeoordelingslijst om sociale steun te meten. Gedragstherapie. 1992;25:27-46.

18. Huiskes CJAE, Kraaimaat FW, Bij|sma JWJ. IRGL, invloed van reuma op gezondheid en leefwijze. Zelfbeoordelingslijst. St Radboud, Nijmegen: Afdeling Medische Psychologie, Universitair Medisch Centrum; 2004

19. Varni JW, Burwinkle TM, Seid M. The PedsQL 4.0 as a school population health measure: feasibility, reliability, and validity. Qual Life Res. 2006;15:203-15.

20. Beck AT, Guth D, Steer RA, Ball R. Screening for major depression disorders in medical inpatients with the Beck depression inventory for primary care. Behav Res Ther. 1997:35:785-91.

21. Custers JAE, de Laat P, Koene S, Smeitink J, Janssen MCH, Verhaak C. Fear of disease progression in carriers of the m.3243A > G mutation. Orphanet J Rare Dis. 2018;13:203.

22. Verhaak $C$, de Laat $P$, Koene $S$, Tibosch $M$, Rodenburg $R$, de Groot I, et al. Quality of life, fatigue and mental health in patients with the m.3243A > G mutation and its correlates with genetic characteristics and disease manifestation. Orphanet J Rare Dis. 2016;11:25.

23. Pinquart $M$, Shen $Y$. Behavior problems in children and adolescents with chronic physical illness: a meta-analysis. J Pediatr Psychol. 2011;36:1003-16.

24. Perrin EC, Stein RE, Drotar D. Cautions in using the child behavior checklist: observations based on research about children with a chronic illness. J Pediatr Psychol. 1991;16:411-21.

25. Parikh S, Karaa A, Goldstein A, Bertini ES, Chinnery PF, Christodoulou J, et al. Diagnosis of 'possible' mitochondrial disease: an existential crisis. J Med Genet. 2019;56:123-30.

26. Mishel MH. Theories of uncertainty in illness. In: Smith MJ, Liehr PR, editors. Middle range theory for nursing. 3rd ed. New York: Springer Publishing Company, LLC; 2014. p. 53-86.

27. Anderson M, Elliott EJ, Zurynski YA. Australian fmailies living with rare disease: experiences of diagnosis, health services use and needs for psychosocial support. Orphanet I rare dis. 2013;8:22.

28. Zurynski Y, Deverell M, Dalkeuth T, Johnson S, Christodoulou J, Leonard H. Autstralian children living with rare diseases: experiences of diagnosis and perceived consequences of diagnostic delays. Orphanet J rare dis. 2017;12:86.

\section{Publisher's Note}

Springer Nature remains neutral with regard to jurisdictional claims in published maps and institutional affiliations.

Ready to submit your research? Choose BMC and benefit from:

- fast, convenient online submission

- thorough peer review by experienced researchers in your field

- rapid publication on acceptance

- support for research data, including large and complex data types

- gold Open Access which fosters wider collaboration and increased citations

- maximum visibility for your research: over $100 \mathrm{M}$ website views per year

At BMC, research is always in progress.

Learn more biomedcentral.com/submissions 